\title{
BMJ A cluster-randomised, parallel group, open controlled intervention study of genetic prostate cancer risk assessment and use of PSA tests in general practice - the ProCaRis study: study protocol
}

To cite: Kirkegaard $P$, Vedsted P, Edwards A, et al. A cluster-randomised, parallel group, controlled intervention study of genetic prostate cancer risk assessment and use of PSA tests in general practice-the ProCaRis study: study protocol. BMJ Open 2013;3:e002452. doi:10.1136/bmjopen-2012002452

- Prepublication history for this paper are available online. To view these files please visit the journal online (http://dx.doi.org/10.1136/ bmjopen-2012-002452).

Received 21 December 2012 Revised 23 January 2013 Accepted 24 January 2013

This final article is available for use under the terms of the Creative Commons Attribution Non-Commercial 2.0 Licence; see http://bmjopen.bmj.com

${ }^{1}$ Research Unit for General Practice \& Research Centre for Cancer Diagnosis in Primary Care-Aarhus University, Aarhus C, Denmark

${ }^{2}$ School of Medicine, Cochrane Institute of Primary Care and Public Health, Cardiff University, Cardiff, UK

Correspondence to Dr Pia Kirkegaard; pia.kirkegaard@alm.au.dk, p.kirkegaard@gmail.com

\section{ABSTRACT}

Introduction: Unsystematic screening for prostate cancer (PCa) is common, causing a high number of false-positive results. Valid instruments for assessment of individual risk of PCa have been called for. A DNA-based genetic test has been tested retrospectively. The clinical use of this test needs further investigation. The primary objective is to evaluate the impact on the use of prostate-specific antigen (PSA) tests of introducing genetic PCa risk assessment in general practice. The secondary objectives are to evaluate PCa-related patient experiences, and to explore sociocultural aspects of genetic risk assessment in patients at high PCa risk. Methods and analysis: The study is a clusterrandomised, controlled intervention study with practice as the unit of randomisation. We expect 140 practices to accept participation and include a total of 1244 patients in 4 months. Patients requesting a PSA test in the intervention group practices will be offered a genetic PCa risk assessment. Patients requesting a PSA test in the control group practices will be handled according to current guidelines. Data will be collected from registers, patient questionnaires and interviews. Quantitative data will be analysed according to intention-to-treat principles. Baseline characteristics will be compared between groups. Longitudinal analyses will include time in risk, and multivariable analysis will be conducted to evaluate the influence of general practitioner and patient-specific variables on future PSA testing. Interview data will be transcribed verbatim and analysed from a social-constructivist perspective.

Ethics and dissemination: Consent will be obtained from patients who can withdraw from the study at any time. The study provides data to the ongoing conceptual and ethical discussions about genetic risk assessment and classification of low-risk and high-risk individuals. The intervention model might be applicable to other screening areas regarding risk of cancer with identified genetic components, for example, colon cancer. The study is registered at the ClinicalTrials.gov (Identifier: NCT01739062).

\section{ARTICLE SUMMARY}

Article focus

The objectives of this study are

- To evaluate the impact on the use of prostatespecific antigen (PSA) tests of introducing genetic prostate cancer $(\mathrm{PCa})$ risk assessment in general practice.

- To evaluate PCa-related patient experiences.

- To explore sociocultural aspects of genetic PCa risk assessment in patients at high $\mathrm{PCa}$ risk.

Key messages

- Use of PSA tests in unsystematic screening for $\mathrm{PCa}$ increases the risk of overdiagnosis and overtreatment of indolent cancers. Valid instruments for individual PCa risk assessment have been called for.

- Retrospective studies of genetic PCa risk assessment have shown promising results in stratifying high-risk and low-risk individuals.

- Use of genetic PCa risk assessment may reduce the number of low-risk individuals who get screened unsystematically.

\section{BACKGROUND}

Prostate cancer $(\mathrm{PCa})$ is the most common cancer type among men in Europe. ${ }^{1}$ The strongest risk factors are old age, positive family history and black race. ${ }^{2} \mathrm{PCa}$ is associated with increased production of the serum marker prostate-specific antigen (PSA). The preferred method for early detection of PCa in older men with a family history of PCa is the PSA test, although the method is imprecise. $^{3}{ }^{4}$ Nearly 1055 men need to undergo PSA screening and $37 \mathrm{PCa}$ cases need to be detected in order to prevent one death from PCa. ${ }^{5}$ Treatment options include surgery, radiotherapy and hormone therapy, 


\section{ARTICLE SUMMARY}

Strengths and limitations of this study

- The study adds a genetic component to an already existing risk assessment tool for PCa which employs family history taking. ${ }^{8}$ Thus, we expect to see an increase in the proportion of patients stratified to high risk, and a reduction in the number of patients stratified to low risk who get proceeded by normal PSA test. If, on the contrary, patients stratified to low risk continue to request preceded by normal PSA tests, the overall consequence might be an unwanted increase in the use of PSA tests. We expect, however, to see a decrease in the number of low-risk patients requesting a preceded by normal PSA test because the genetic risk assessment may work as a decision support for unsure patients who are not at high risk according to the conventional risk assessment tool with family history taking.

- Screening for cancer has dominated the health policy debate for several years. ${ }^{75758}$ Recent studies have shown the limited effects of general screening for PCa. ${ }^{4} \quad 1359$ New national guidelines for screening with PSA tests in men with familia disposition are likely to be introduced during the study period. A more restrictive guideline may reduce the effect of introducing genetic risk assessment on the use of PSA, compared between the intervention group and the control group.

- The study provides the opportunity to study cancer risk perception in male patients who have been under-represented in the literature about cancer risk perception. ${ }^{33} 60$ In this way, the study may contribute to the ongoing conceptual and ethical discussions about genetic risk assessment and classification of high-risk individuals. ${ }^{4761-64}$

- The project is based on the present Danish recommendation to PSA test only men who have two close relatives with $\mathrm{PCa}$, which approximates a lifetime risk of $33 \%$. A certain proportion of those recommended not to have a PSA test will be diagnosed at a later stage with PCa, and a PSA test might have led to an earlier diagnosis. In this project, we aim to detect men who may benefit from systematic PSA tests. We maintain a cut-off point of $33 \%$ lifetime risk before a patient is recommended screening with PSA tests. This means that $10 \%$ of those with a normal PSA will be recommended to have the test done, whereas none of those with a normal PSA today are currently recommended to be tested, unless they have two or more close relatives with $\mathrm{PCa}$. We know very little about the benefits and disadvantages for this group of joining a screening programme. However, the alternative at the moment is that $26 \%$ of patients get a preceded by normal test and thus establish their own ad hoc PSA screening programme. In comparison, the approach taken by this study offers a systematic and potentially better alternative and it should be rigorously evaluated.

often followed by significant complications such as sexual dysfunction, urinary incontinence and lowered quality of life. ${ }^{6}$ A systematic Cochrane review from 2011 showed insufficient evidence to support general screening for PCa with current methods (PSA tests, digital rectal exam and biopsies). ${ }^{7}$ General screening with PSA test has not been recommended by most health authorities due to the high number of false-positive results and the risk of overdiagnosis as well as overtreatment, and in Denmark,
PSA screening is recommended only for men with a minimum of two close relatives with $\mathrm{PCa}$, which approximates a lifetime risk of $33 \%$ of being diagnosed with $\mathrm{PCa}^{8}$ In spite of this, up to $26 \%$ of all tests requested in general practice can be categorised as ipreceded by normal', meaning tests which are performed within 2 years after a normal test. Tests in this category may indicate unsystematic screening. ${ }^{9}$

By now, scientific advancement in genome-wide association studies has identified more than 40 genetic variants for PCa risk, the so-called single nucleotide polymorphisms (SNPs). The individual risk of PCa accumulates with the increasing number of these variants. The risk is doubled if a patient has familial disposition as well. In retrospective studies, non-genetic risk prediction models were compared to risk prediction models containing both non-genetic factors and SNP analyses. The genetic models had a significantly higher specificity than the non-genetic models. ${ }^{10-12}$ It has been argued that genetic PCa risk assessment could reduce the use of PSA tests, saving it for patients at high risk of PCa. ${ }^{11} 1314$ This genetic PCa risk assessment tool needs further investigation in a clinical setting.

Previous studies have indicated that men are interested in receiving genetic PCa risk assessments. ${ }^{15-18}$ Men's reactions to information about PCa family history have shown no significant long-term psychological distress, but the studies remain small and inconclusive. ${ }^{18-22}$ There is a vast literature on female-specific genetic cancer risk assessment and its consequences for clinical practice and female patient behaviour. ${ }^{23-28}$ Few studies about male carriers of the BRCA1/2 gene associated with breast cancer have been conducted. ${ }^{29-32}$ Studies in related fields have shown a gendered difference in health-related behaviour and perception of risk, indicating that men more than women worry about health-related risks that influence work life and sexual life. ${ }^{33-38}$ Thus, male-specific genetic cancer risk assessment is likely to be influenced by sociocultural contexts not described in the current literature.

The main study hypothesis is that genetic information about low risk of PCa can reduce the number of patients who get a PSA test as part of unsystematic screening.

\section{DESIGN AND METHODS \\ Setting}

Denmark consists of 98 municipalities divided between 5 regions. Central Region Denmark has 19 municipalities and 1.2 mio. inhabitants. It has five large somatic hospital units, each comprising between two and five region hospitals or health centres. The Aarhus University Hospital is the largest hospital unit, including 54 clinical departments and 12 research units. The Department of Molecular Medicine (MOMA) runs research projects related to $\mathrm{PCa}$, bladder cancer and colon cancer, and performs molecular diagnostics. MOMA performs genetic analysis and genetic risk assessment for PCa in this study. 


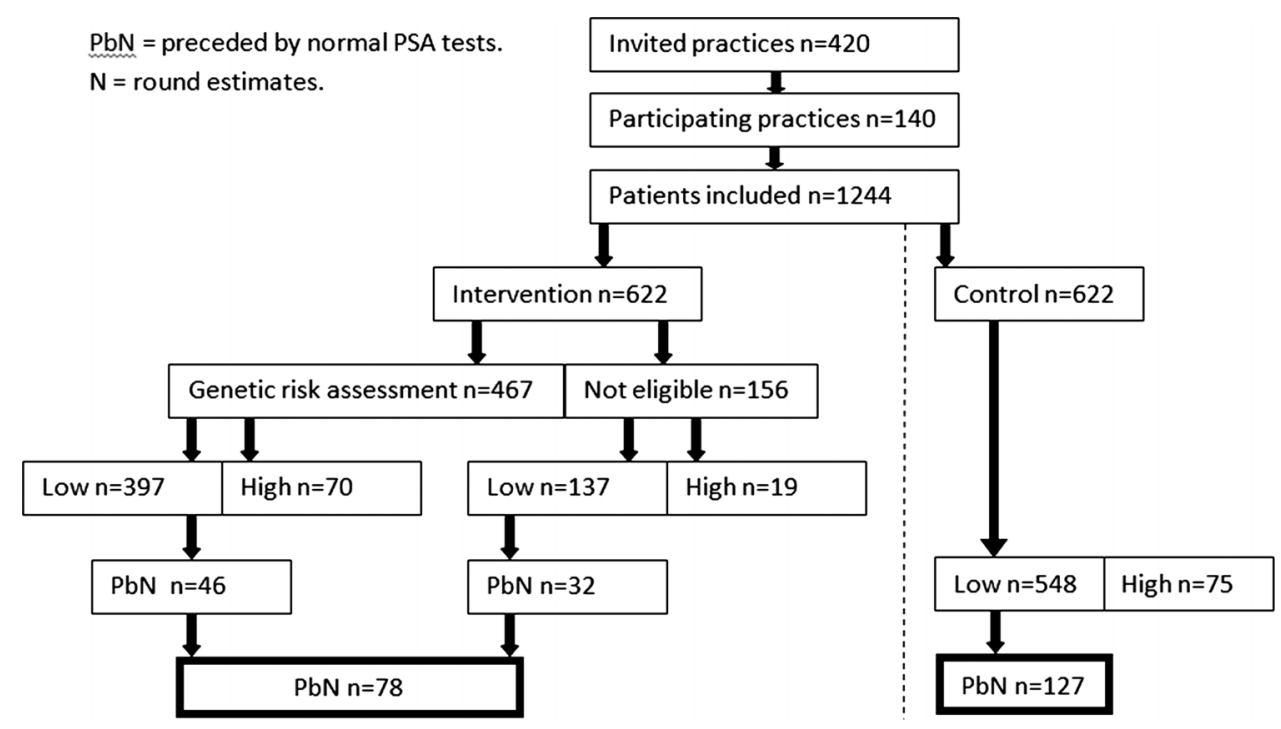

Figure 1 Participants.

The Central Region Denmark has 420 general practices. General practitioners (GPs) act as gatekeepers to the rest of the healthcare system, except for certain specialist medical services and emergencies. Healthcare is financed largely through taxes, and patients have free access to medical service in general practice. It is mandatory for GPs to use electronic patient records, and most test requisitions and test results are transferred electronically. ${ }^{39}$

\section{Participants}

The study will be a blocked cluster-randomised, parallel group, controlled intervention study with practice as the unit of randomisation (figure 1). The 420 general practices in Region Central Denmark will be invited to participate. One-third of the practices are expected to accept participation. Blocking will be applied to assure the best possible balance between groups with respect to practice size (number of doctors). Randomisation will be undertaken by a program developed by an independent statistician to ensure allocation concealment.

On an average, each practice makes approximately 41 PSA test requisitions per year. ${ }^{9}$ Two-thirds of the tests are incident PSA tests or preceded by normal PSA tests.

Eligible for inclusion are all patients listed at the randomised practices who receive a PSA test within the study period, unless subject to one of the following exclusion criteria: age over 80 years; elevated PSA level ( $>4 \mathrm{ng} / \mathrm{ml}$ ) concurrently or within previous 2 years; prostate or bladder disease; and PCa.

Patients of East-Asian or Afro-American descent or those unable to speak or read Danish (as assessed by the GP) will not be offered the genetic risk assessment regardless of the randomisation group, but will be included in the intention-to-treat analysis as well as patients declining to participate. In all, $75 \%$ of the patients in the group randomised to intervention are expected to actually receive the genetic risk assessment.

\section{Intervention}

The recommendation in the genetic PCa risk assessment reply is based on the present Danish recommendation to screen only individuals who have two close relatives with PCa which is associated with a $33 \%$ lifetime risk of being diagnosed with $\mathrm{PCa}$, defined as high risk. ${ }^{8}$ In this study, low-risk patients (with a risk below 33\%) will be discouraged from getting PSA tests in the future, if not otherwise indicated. Patients with two close relatives with $\mathrm{PCa}$ and patients with a high genetic risk (>33\%) will be encouraged to receive regular PSA tests, that is, screening.

The intervention consists of three steps:

1. When the GP makes an electronic PSA requisition for a patient, a pop-up questionnaire is shown on the GP's screen with inclusion criteria for the patient. If the patient fulfils the inclusion criteria, information about a genetic risk assessment for PCa and its implications is shown on the screen for the GP and the patient to discuss. The information is printed out for the patient who can bring it home for deliberation. The GP can make an ordinary PSA test requisition if the patient does not fulfil the inclusion criteria, or if the patient wishes not to participate in the study.

2. If the patient wishes to have a genetic PCa risk assessment, two blood samples will be taken: one for the PSA test and one for the genetic PCa risk assessment (SNP test). The PSA test will be analysed and the result will be reported back to the GP according to the usual procedure. MOMA will assess the genetic risk by identifying the relevant SNPs.

3. The GP will receive the result of the genetic risk assessment as an electronic reply from MOMA. If the genetic risk is low, the reply contains a recommendation for the patient to refrain from further PSA testing. If the risk is high, the reply contains a recommendation to have regular PSA tests. 


\section{Pilot study}

The three steps of the intervention were developed and tested in a pilot study. Paper drafts for the screen dumps with the information and the reply were presented to 12 patients who had a PSA test. Five of the patients wished to have a genetic PCa risk assessment and provided a blood sample. The GPs and the patients were interviewed about the feasibility of the information and the reply. After this, the wording in the decision aid and the reply was changed from a numbered format (percentage) to a dichotomised risk format (high risk vs low risk). Then, a research requisition system linked to the standard requisition system was created. It contained a module for inclusion and information based on the feedback of the GPs and patients in the pilot. An electronic pathway between standard laboratories and the research laboratory was established in order to transfer the result of the genetic PCa risk assessment back to the GP through the standard requisition. The next step in the pilot study was to include five research practices to test the electronic pathway. They recruited 34 patients for a genetic PCa risk assessment. Feedback from the GPs and the patients showed no significant barriers in the set-up. The questionnaires were developed, validated by five patients and refined for the intervention.

\section{Outcomes}

The primary outcome is the number of patients at low risk who get a preceded by normal PSA test within 2 years, that is, a PSA test which is performed within 2 years after a PSA test with a normal result.

The secondary outcomes are patient intentions to get a PSA test, satisfaction, healthcare use and proportion of patients stratified to high risk. In addition, the number of included patients will be compared between groups, as the option to receive a genetic risk assessment may influence the propensity to request services in general practice (table 1).
Data about GP-seeking frequency will be collected, with a view to assessing association with the use of PSA tests.

Data about visits to the Department of Urology, PCa diagnosis, PCa treatment and PCa death are assumed to be infrequent in the relatively short study period. They are, however, assessed to be important in a potential long-term follow-up.

The data about the number of patients at low risk who get a PSA test and healthcare use will be collected from registers from laboratories and hospital administrative systems. The questionnaires will contain questions about intentions to get a PSA test, questions about psychological well-being and questions about satisfaction and risk communication from the Comrade Scale. ${ }^{40}$ The questions have been validated in Danish. To avoid the effect of cointervention in using patient questionnaires, patients in both groups will receive questionnaires at 1 month (baseline), 1 year and 2 years follow-up, or be left untouched, only followed in registers. Questionnaires will be scanned and coded electronically by data entry personnel, and in the case of missing or apparently erroneous data, two of the authors will discuss the interpretation until agreement is reached. All data will be checked for errors before entering a customised database.

The social aspects of being genetically risk assessed will be explored with the following research question: in which ways does the social and cultural context influence the interpretations and management of genetic risk assessment of PCa? Data will be produced through anthropological fieldwork including interviews with approximately 20 patients at high genetic risk of $\mathrm{PCa} .{ }^{41-43}$ The interviews will take place in the patients' homes and, if possible, as a family interview or joint interviews. ${ }^{44}$ Each patient (with family) will be interviewed 1 month after the genetic test result, and reinterviewed 1 year and 2 years after this first interview. Participant observation will be conducted in consultations where the high-risk patients consult their GPs for a preceded by normal PSA test. The interview data

Table 1 Outcomes and data

\begin{tabular}{ll}
\hline Outcomes & Data \\
\hline Primary outcomes & Register data \\
No. of low-risk patients who get a preceded by normal PSA test (ie, any tests after the index sample) & Questionnaire data \\
Secondary outcomes & Register data \\
Intentions to get the PSA test & \\
Satisfaction with risk communication and decision-making & Psychological well-being \\
Proportion of high-risk patients & Number of \\
Prostate biopsies & \\
Visits to the GP & \\
Inpatient and outpatient visits to the Department of Urology & \\
Surgical prostate treatments & \\
Incident PCa & PCa deaths
\end{tabular}


and field notes from the anthropological fieldwork will be handled using the NVivo software.

\section{Sample size}

Currently, approximately $26 \%$ of patients with a normal PSA test get a repeated test within 2 years. Guesstimating $12 \%$ of the initially tested to have a familiar disposition of PCa, and assuming twice as high a frequency of repeated testing compared to patients without familiar disposition, it is estimated that the proportion having a preceded by normal test is approximately 23\% among these low-risk patients. It is assumed in this study that this proportion can be reduced by half among the $75 \%$ in the intervention group, who are expected to receive the genetic PCa risk assessment. This sums to an overall retesting frequency of $15 \%$ in the intervention group as defined by intention-to-treat. Assuming that $33 \%$ of practices in the region accept participation and $86-88 \%$ of initially tested patients are categorised into low risk (a small difference in this proportion is expected between the intervention and control groups), a study period of 4 months will accommodate the inclusion of 1244 patients, of which 1082 will be classified into low risk. The study period will be extended if necessary to reach the target sample size. Allowing for a design effect of 1.2 , this can provide a study power of $89.8 \%$ at a standard significance level of $5 \%$. As the use of PSA tests is registry based, correction for non-response is not relevant, and thus the study is adequately powered, though a minor loss to follow-up due to emigration, death or PCa diagnosed without further PSA tests must be expected.

\section{Data analysis}

Quantitative data will be analysed according to intention-to-treat principles, ${ }^{45}$ that is, in the analysis, patients will be assigned to the group to which they were randomised, regardless of their subsequent compliance to the intervention programme. Baseline characteristics will be compared between groups. Longitudinal analyses will include time in risk and the patients will be censored if they get $\mathrm{PCa}$, die or migrate. Multivariable analysis will be conducted to evaluate the influence of GP and patient-specific variables on future PSA testing.

The data from the interviews will be transcribed verbatim and analysed thematically using the Nvivo software. The epistemological approach stems from social constructivist theories, ${ }^{46-53}$ and theories about social practice and meanings attributed to perception and construction of risks will be applied to the data with a view to adding empirical and theoretical insights into the field of social risk. ${ }^{54-56}$

\section{DISCUSSION AND PERSPECTIVES}

During the last few years, an increasing number of tests for risk of disease have been developed. The Danish healthcare system provides a unique platform for evaluation of such tests: there is a $100 \%$ electronic exchange of data between hospitals, laboratories and general practice; every patient has a personal identification number; and the patient registers are of high quality and easily accessible, containing information on procedures, diagnosis, test and healthcare use. ${ }^{39}$ The development of an intervention to support genetic risk assessment for PCa in general practice might also be applicable to other screening areas regarding risk of cancer, for example, cervical cancer, breast cancer and colon cancer.

Acknowledgements This study is part of a research alliance entitled 'Molecular Prediction of Prostate Cancer Risk and Aggressiveness' (MolPros). Research partners are Aarhus University Hospital and Aarhus University, Denmark; USC/ Norris Comprehensive Cancer Center in Los Angeles, USA; University Erlangen-Nuernberg, Germany; and Beijing Genomics Institute, China. The overall aims are to identify new markers for PCa aggressiveness and to develop bioinformatics software. Danish researchers conduct the clinical research exclusively in this alliance.

Collaborators MolPros-Translational Cancer Research Alliance. Web page: www.molpros.dk.

Contributors FB and PV conceived the study and made the original proposal. $A E$ contributed to the design and conceptualisation. MFG contributed to the design and made the statistical calculations; PK contributed to the design and conceptualisation, and prepared the manuscript. All authors read and approved the manuscript. Data will be collected by PK and analysed by all authors, and result in approximately eight scientific publications in Open Access journals according to the outcomes. In addition, the results will be disseminated in the general practice community and in relevant public media.

Funding The study was supported by the Danish Research Council for Strategic Research (Journal no. 10-092796) and the Sector Skills Council for Quality and Postgraduate Training (KEU) (Journal no. 1-30-72-93-11).

\section{Competing interests None.}

Patient consent Patients receive oral and written information about participation in the consultation with the general practitioner. The patients can either decide in the consultation to accept participation or take the written information home for further contemplation. If a patient declines participation, he will not be asked to participate later. The patients can withdraw from having their genetic PCa risk assessment revealed during the weeks it takes before the reply is ready. The written patient information will refer to a website about the study, and a project coordinator can be contacted for questions or support.

Ethics approval Danish Scientific-Ethical Committee (Journal no. 1-10-72-43-12).

Provenance and peer review Not commissioned; internally peer reviewed.

Permissions and registrations The study will be conducted according to the Helsinki Declaration principles. It has been notified to the Danish Data Protection Agency (Journal no. 2011-41-6904) and collection of data will be handled according to their guidelines. The study has obtained permission from the Danish Scientific-Ethical Committee (Journal no. 1-10-72-43-12). The study is registered at the ClinicalTrials.gov (Identifier NCT01739062).

\section{REFERENCES}

1. Damber J, Aus G. Prostate cancer. Lancet 2008;371:1710-21.

2. Hoffman RM. Screening for prostate cancer. $N$ Engl J Med 2011;365:2013-19.

3. Kim J, Davis JW. Prostate cancer screening - time to abandon one-size-fits-all approach? JAMA 2011;306:2717-18.

4. Schroder FH, Hugosson J, Roobol MJ, et al. Screening and prostate-cancer mortality in a randomized European study. $N$ Engl J Med 2009;360:1320-8.

5. Schroder FH, Hugosson J, Roobol MJ, et al. Prostate-cancer mortality at 11 years of follow-up. N Engl J Med 2012;366:981-90.

6. Smith DP, King MT, Egger S, et al. Quality of life three years after diagnosis of localised prostate cancer: population based cohort study. BMJ 2009;339:b4817. 
7. Ilic D, O'Connor D, Green S, et al. Screening for prostate cancer: an updated Cochrane systematic review. BJU Int 2011;107:882-91.

8. Hansen BL, Lose G, McNair SB, et al. [DSAM: klinisk vejledning for almen medicin. Udredning og behandling af nedre urinvejssymptomer hos mænd og kvinder]. 1st edition. Viby J, Scanprint, eds. Dansk Selskab for Almen Medicin og Fonden for Tidsskrift for Praktisk Lægegerning. 2009 .

9. Mukai TO, Bro F, Pedersen KV, et al. Use of prostate-specific antigen testing. Ugeskr Laeger 2010;172:696-700.

10. Aly M, Wiklund $\mathrm{F}, \mathrm{Xu} \mathrm{J}$, et al. Polygenic risk score improves prostate cancer risk prediction: results from the Stockholm-1 cohort study. Eur Urol 2011;60:21-8.

11. Vickers AJ, Cronin AM, Roobol MJ, et al. The relationship between prostate-specific antigen and prostate cancer risk: the Prostate Biopsy Collaborative Group. Clin Cancer Res 2010;16:4374-81.

12. Jin G, Lu L, Cooney KA, et al. Validation of prostate cancer risk-related loci identified from genome-wide association studies using family-based association analysis: evidence from the International Consortium for Prostate Cancer Genetics (ICPCG). Hum Genet 2012;131:1095-103.

13. Zhu X, Albertsen PC, Andriole GL, et al. Risk-based prostate cancer screening. Eur Urol 2012;61:652-61.

14. Roobol MJ, Steyerberg EW, Kranse R, et al. A risk-based strategy improves prostate-specific antigen-driven detection of prostate cancer. Eur Urol 2010;57:79-85.

15. Doukas DJ, Li Y. Men's values-based factors on prostate cancer risk genetic testing: a telephone survey. BMC Med Genet 2004;5:28.

16. Bratt $\mathrm{O}$, Kristoffersson $U$, Lundgren $\mathrm{R}$, et al. Sons of men with prostate cancer: their attitudes regarding possible inheritance of prostate cancer, screening, and genetic testing. Urology 1997;50:360-5.

17. Bratt O, Damber JE, Emanuelsson M, et al. Risk perception, screening practice and interest in genetic testing among unaffected men in families with hereditary prostate cancer. Eur J Cancer 2000;36:235-41.

18. James KM, Cowl CT, Tilburt JC, et al. Impact of direct-to-consumer predictive genomic testing on risk perception and worry among patients receiving routine care in a preventive health clinic. Mayo Clin Proc 2011;86:933-40.

19. Jacobsen PB, Lamonde LA, Honour M, et al. Relation of family history of prostate cancer to perceived vulnerability and screening behavior. Psychooncology 2004;13:80-5.

20. Bratt O, Emanuelsson M, Gronberg H. Psychological aspects of screening in families with hereditary prostate cancer. Scand J Urol Nephrol 2003;37:5-9.

21. Bratt O, Damber JE, Emanuelsson M, et al. Risk perception, screening practice and interest in genetic testing among unaffected men in families with hereditary prostate cancer. Eur J Cancer2000; 36:235-41.

22. Spain $\mathrm{P}$, Carpenter WR, Talcott JA, et al. Perceived family history risk and symptomatic diagnosis of prostate cancer: the North Carolina Prostate Cancer Outcomes study. Cancer 2008;113:2180-7.

23. Julian-Reynier C, Mancini J, Mouret-Fourme E, et al. Cancer risk management strategies and perceptions of unaffected women 5 years after predictive genetic testing for BRCA1/2 mutations. Eur $J$ Hum Genet 2011;19:500-6.

24. Leblond D, Bredart A, Dolbeault S, et al. Cognitive, emotional and behavioral impact of an uncertain outcome after study of BRCA1/2 review of the literature. Bull Cancer 2011:98:184-98.

25. Quillin JM, Bodurtha JN, McClish D, et al. Genetic risk, perceived risk, and cancer worry in daughters of breast cancer patients. $J$ Genet Couns 2011;20:157-64.

26. Menko FH, Jansen AM, Stoel RD, et al. Perceiving cancer-risks and heredity-likelihood in genetic-counseling: how counselees recall and interpret BRCA 1/2-test results. Clin Genet 2011;79:207-18.

27. Henneman L, Timmermans DR, Bouwman CM, et al. 'A low risk is still a risk': exploring women's attitudes towards genetic testing for breast cancer susceptibility in order to target disease prevention. Public Health Genomics 2011;14:238-47.

28. Hallowell N, Foster C, Eeles R, et al. Accommodating risk: responses to BRCA1/2 genetic testing of women who have had cancer. Soc Sci Med 2004;59:553-65.

29. Graves KD, Gatammah R, Peshkin BN, et al. BRCA1/2 genetic testing uptake and psychosocial outcomes in men. Fam Cancer 2011;10:213-23.

30. Schiffman SC, Chagpar AB. Does a family history of male breast cancer influence risk perception and use of genetic testing? $\mathrm{Am}$ Surg 2010;76:879-82.

31. Hallowell N, Ardern-Jones A, Eeles R, et al. Communication about genetic testing in families of male BRCA $1 / 2$ carriers and non-carriers: patterns, priorities and problems. Clin Genet 2005;67:492-502.
32. Hallowell N, Ardern-Jones A, Eeles R, et al. Men's decision-making about predictive BRCA1/2 testing: the role of family. J Genet Couns 2005; 14:207-17.

33. White A, Richardson N. Gendered epidemiology: making men's health visible in epidemiological research. Public Health 2011;125:407-10.

34. White AK, Thomson CS, Forman D, et al. Men's health and the excess burden of cancer in men. Eur Urol Suppl 2010;9:467-70.

35. Bates LM, Hankivsky O, Springer KW. Gender and health inequities: a comment on the final report of the WHO commission on the social determinants of health. Soc Sci Med 2009;69:1002-4.

36. Byrnes JP, Miller DC, Schafer WD. Gender differences in risk taking a meta-analysis. Psychol Bull 1999;125:367-83.

37. Schubert R. Analyzing and managing risks-on the importance of gender differences in risk attitudes. Manage Finance 2006;32:706.

38. Gustafson PE. Gender differences in risk perception: theoretical and methodological perspectives. Risk Anal 1998;18:805.

39. Pedersen KM, Andersen JS, Sondergaard J. General practice and primary health care in Denmark. J Am Board Fam Med 2012;25 (Suppl 1):S34-8.

40. Edwards A, Elwyn G, Hood K, et al. The development of COMRADEa patient-based outcome measure to evaluate the effectiveness of risk communication and treatment decision making in consultations. Patient Educ Couns 2003;50:311-22.

41. Hilden PK, Middelthon AL. Qualitative methods in medical researchan ethnographic perspective. Tidsskr nor Laegeforen 2002;122:2473-6.

42. Hammersley M, Atkinson P. Ethnography. Principles in practice. London: Routledge, 2002.

43. Reeves S, Kuper A, Hodges BD. Qualitative research methodologies: ethnography. BMJ 2008;337:a1020.

44. Seale C, Charteris-Black J, Dumelow C, et al. The effect of joint interviewing on the performance of gender. Field Methods 2008;20:1-22.

45. Schulz KF, Altman DG, Moher D. For the CONSORT Group. CONSORT 2010 Statement: updated guidelines for reporting parallel group randomised trials. BMJ 2010;340:c332.

46. Tulloch J, Lupton D. Risk and everyday life. London: SAGE Publications, 2003.

47. Lupton D. Risk. London: Routledge, 1999.

48. Douglas M. Risk and blame: essays in cultural theory. London: Routledge, 1994.

49. Kavanagh AM, Broom DH. Embodied risk: my body, myself? Soc Sci Med 1998;46:437-44.

50. Novas C, Rose N. Genetic risk and the birth of the somatic individual. Econ Soc 2000;29:485-513.

51. Lock M. Part 3: the human in the body demoting the genetic body. Anthropologica 2009;51:159-72.

52. Lock M, Freeman J, Chilibeck G, et al. Susceptibility genes and the question of embodied identity. Med Anthropol Q 2007;21:256-76.

53. Chilibeck G, Lock M, Sehdev M. Postgenomics, uncertain futures, and the familiarization of susceptibility genes. Soc Sci Med 2011;72:1768-75.

54. Han PK, Klein WM, Lehman TC, et al. Laypersons' responses to the communication of uncertainty regarding cancer risk estimates. Med Decis Making 2009;29:391-403.

55. Lee SJ. Uncertain futures: individual risk and social context in decision-making in cancer screening. Health Risk Soc 2010;12:101-17.

56. Boholm Å. The cultural nature of risk: can there be an anthropology of uncertainty? Ethnos 2003;68:159.

57. Bleyer A, Welch HG. Effect of three decades of screening mammography on breast-cancer incidence. $N$ Engl J Med 2012;367:1998-2005.

58. Woloshin S, Schwartz LM, Black WC, et al. Cancer screening campaigns - getting past uninformative persuasion. $N$ Engl J Med 2012;367:1677-9.

59. Hugosson J, Carlsson S, Aus G, et al. Mortality results from the Goteborg randomised population-based prostate-cancer screening trial. Lancet Oncol 2010;11:725-32.

60. Rantala J, Platten U, Lindgren G, et al. Risk perception after genetic counseling in patients with increased risk of cancer. Hered Cancer Clin Pract 2009;7:15.

61. Conrad P. The shifting engines of medicalization. J Health Soc Behav 2005;46:3-14.

62. Timmermans S, Haas S. Towards a sociology of disease. Sociol Health IIIn 2008;30:659-76.

63. Lipworth WL, Davey HM, Carter SM, et al. Beliefs and beyond: what can we learn from qualitative studies of lay people's understandings of cancer risk? Health Expect 2010;13:113-24.

64. Petersen A, Lupton D. The new public health: health and self in the age of risk. London: SAGE, 1996. 